\title{
RESPONSIBILITY TO THE FUTURE
}

\author{
Marie Mikušová ${ }^{1}$ \\ ${ }^{1}$ Vysoká škola báňská-Technická univerzita Ostrava, Ekonomická fakulta, Sokolská třída 33, 70121 Ostrava \\ Email:marie.mikusova@vsb.cz
}

\begin{abstract}
The article focuses on responsible behavior for the future. Its aim is to emphasize that the future of all depends on the behavior of every individual, every organization. The behavior of these two entities are monitored in two areas. The first area focuses on individual and his behavior. The approaching of responsible behavior of an individual is showed. Factors influencing the level of responsible behavior are divided into three levels: personal approach to the responsible living, conditions for education for responsible living, subsystems of education and training. The relationship of these levels is pointed, the result of this relationship is the level of the responsibility in behavior. Business is being explored at the second area. It stressed the fact that the business is no longer measured simply by economic outcomes. The concept of Triple Bottom Line (TBL) as the goal of sustainability is explained. People (Human Capital), Planet (Natural Capital) and Profit have become essential items for the assessment of business by TBL Reporting. The arguments for the concept TBL and against the TBL concept are described. In conclusion, the author formulated the need to cover the education for responsible living since early childhood. The challenge for business in this area is the implementation of triple bottom line reporting.
\end{abstract}

Keywords: business, future, individual, responsible living, triple bottom line.

JEL classification: M14

Doručeno redakci: 1.4.2011; Recenzováno: 6.2.2013; 14.1.2013; 7.2.2013; Schváleno k publikování: 13.3.2013

\section{Introduction}

The problem of responsibility to the future in this time is even more pressing if we realise that the economy is not the only region which abides the absence of responsible behavior. From all the sides we are facing many societal, political, cultural and also ethical events connected with responsibility to the future. As an example can serve predatory behavior toward nature, state of natural resources, religious and political strife, misunderstanding of multiculturalism, racism, and also health care system, education, police, judicial system, the crisis in the perception of our own personality or the crisis of values.

The present article focuses on two areas fundamentally affecting the responsibility to the future. This article aims to highlight the responsibility of individuals for the future and to show the way in which this responsibility shifts to the business. The first of the areas affecting the future are individuals themselves and their relationship to Responsible Living. The article stresses the important role of each individual in relation to the future and sustainability, namely the importance of individual approach of each of us. A responsible approach to the future can be influenced, individuals can be educated, guided and convinced about the importance of responsible living. The article identifies factors and steps indicating the levels of an individual behavior and directions of the responsible education and training of individuals towards the fulfillment of the requirements for resposible living. The second area is the business itself. Business can be considered as the largest contributor to future threats. But business has tools to secure future. The challenge for business in this area is the implementation of triple bottom line reporting.

Methods used in the course of the research individual areas are not clearly separated. All parts used analytic methods, synthetic methods, comparative methods and creative thinking 
methods, however in different extend. Classification analysis was used for the differentiation between individual approaches to social behavior. Synthesis of knowledge is a condition for the formulation of conclusion. The author clarified functional mechanisms of observed phenomena by integrating of observations in a broader context. The synthesis is not mere sum of individual phenomena but creation of new concepts and new views.

For the purposes of this article the following terms are specified:

Social responsibility of individuals is seen as the responsibility of every individual for his/her actions. Each individual has an obligation to the society because each individual contributes toward ecological, social or cultural causes. The performance of these obligations depends on an individual's morality. Individuals can not deal only with material areas but also support philanthropic issues. Individual social responsibility may be slightly impractical, especially in the modern competitive world, where everyone works for self-interest, but it will succeed if individuals take decisions based on what will benefit a large number of people and respect everyone's fundamental rights (Epstein, 2008). Critics may argue that individuals can make small contributions to society but switching off lights or computers when not in use or waste sorting is also very important.

Corporate social responsibility $(C S R)$ is a form of corporate self-regulation integrated into a business model. CSR policy builts a self-regulating mechanism whereby a business monitors and ensures its active compliance with the spirit of the law and ethical standards (Bornstein, Davis, 2010). CSR is a process with the aim to embrace responsibility for the company's actions and encourage a positive impact through its activities on the environment, consumers, employees, communities, stakeholders (Elkington, 1999). The term "corporate social responsibility" came into common use in the late 1960s and early 1970s after many multinational corporations formed the term stakeholder meaning those on whom an organization's activities have an impact (Meadows, 2008).

The goal of sustainability is the triple bottom lines which are described by "people, planet and profit". The phrase, "people, planet, profit", was coined by John Elkington in 1995 while at SustainAbility, and was later adopted as the title of the Anglo-Dutch oil company Shell's first sustainability report in 1997 (Scofield, 2011).

Triple bottom line (TBL) accounting expands the traditional reporting framework to take into account social and environmental performance in addition to financial performance. In 1981 Spreckley first articulated the triple bottom line in a publication called 'Social Audit - A Management Tool for Co-operative Working' (Scofield, 2011). In this work, he argued that enterprises should measure and report on social, environmental and financial performance. The relationships are presented in Fig. 1. 
Figure 1: Triple bottom line

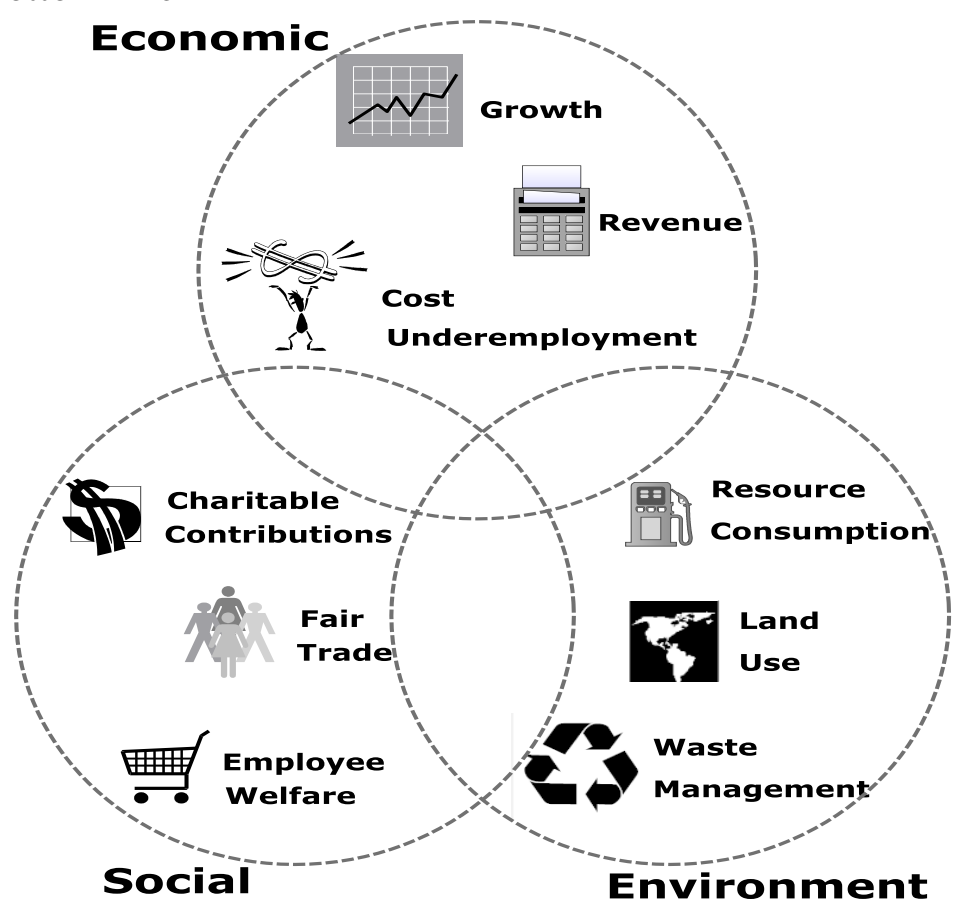

Source: Author

Revised from (Elkington, Hartigan, 2008)

1 Individuals: approaching to responsible behavior and the education system in this area In practice, the goal of responsible behaviour is to defend and shield the organisations and individual oneself from different fateful adverse events, appropriate to ensure their adequate access to already set in situation. Threats of the very existence come from many sources. They come primarily from the concerns about efforts to conserve nature, economical decline, struggle with competition, technological risks or direct threat to the health or lives. These sources also indicate exposed areas, where the education and training of people (starting with young children) agreeabled to behave responsible should be focused on. From the above mentioned follows that a large range of knowledge and skills from different areas are indispensable for the application of really responsible behavior to the future. For better illustration, the stated relations can be expressed in Fig. 2.

Figure 2: Factors influencing the level of responsible behavior

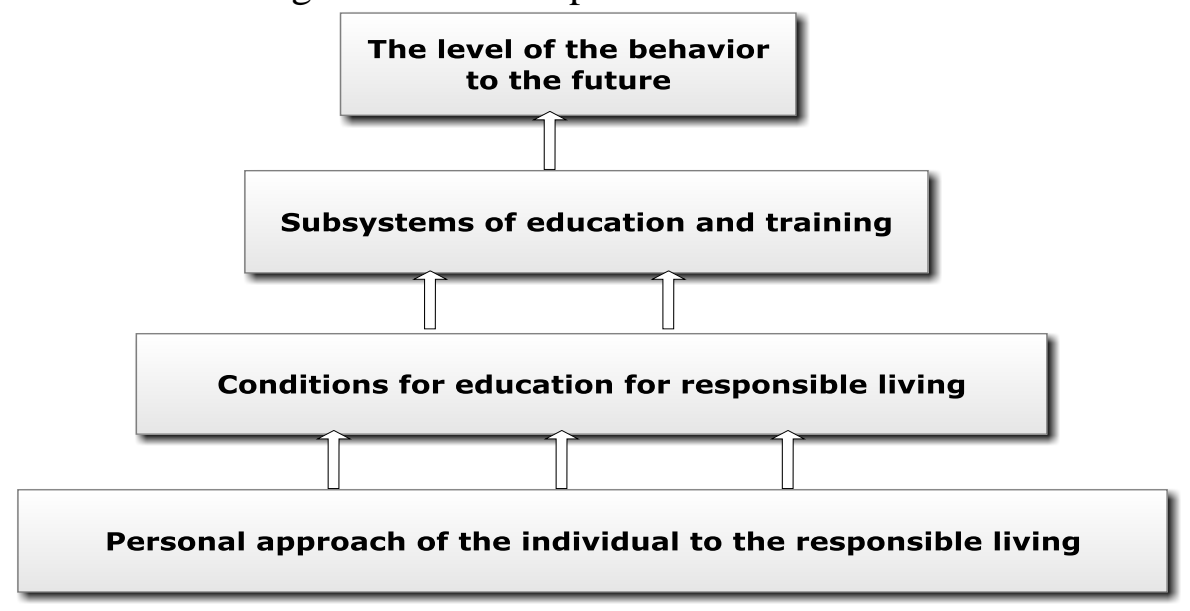

Source: Author 


\section{Factors influencing the level of an individual responsible behavior 2. 1 Personal approach to the responsible living}

The basis for a responsible training for the solution of any problem is an individual personal approach. That's why we are going to tackle the aspects that influence the attitude of an individual to the necessity of responsible behavior. One of the strongest influences impacting an individual is his personality. Sociologists have proved some most vital personality features are unconscious. In this consequence, individuals are often not aware of some important influences impacting their activity (Kets de Vries, Miller, 1984).

One of the most important ways such unconscious influences act is acting through basic own opinions considered to be reasonable and strict, created by a person in relation to himself and surrounding environment. Opinions and ideas on principle influenced personal approach to responsible behavior we should consider in the following five principal fields identified as an organizational culture base (Schein, 2010).

A relation to the respective surroundings: Does a person understands his relation to the surroundings as a relation meaning supremacy, subordination, harmony, searching for proper positions or anything else?

A character of the truth and reality: Of what nature are regulations, methods, individual behaviour in defining what is true and what is not true?

A human nature character: What does it mean "to be a human being" and what human properties are considered to be principal and indispensable? Is a human nature bad, good or neutral?

A human activity character: Based on the above stated opinions, how would people behave in relation to their surroundings, truth and fact, and human nature? To be active, passive, committed to work or subjected to the fate?

A human relations character: What is deemed to be proper relations among people? It is a relation of co-operation or competition, individualism or group, is it based on natural authority, laws or charisma?

For this paper purposes it is going to divide the individuals to two groups: "ready" (hereinafter just "R") - ready or preparing for responsible behavior to the future, understanding its importance, and "not ready" (hereinafter just "N") which are able or willing to deal with a responsibility only at minimum. It is noted such dividing is much simplified.

Now, let's have a look how these two groups differ in their principal opinions and statements. A relation to the respective surroundings: The individuals should clarify their external environment definition and their relation to it. A "R" person understands his surroundings in quite a wide content, trying to conceive also the position of surrounding entities, not undermining the importance of external entities for its activities. A person is perceived friendly, not only as a means for its objective achieving, as it is in case of the "N" person.

A character of the truth and reality: In order to protect their own idea of themselves, the "N" persons apply a great number of protective mechanisms. E.g. idealization is one of the most frequently used mechanisms, i.e. a feeling to be able to achieve everything, which is based on idealization of some people (Pauchant, Mitroff, 1988). 
A human nature character: The "N" persons have tendences to divide internal and external entities to "good", proving them perfectness feeling, and "bad". The "R" persons admit their potentials and real abilities.

A human activity character: The "N" persons often practise a fatalism, by which they prevent themselves from a feeling of a blame. According to them, accidents are accidental, caused by bad luck, a bad star. Such behaviour is dangerous. In its consequences, it diminishes a feeling of the blame and being responsibility for activities, justifying the measures absence.

A human relations character: The " $\mathrm{R}$ " persons utilize simultaneously competition and cooperation, individualism as well as teamwork. The " $\mathrm{N}$ " persons prefer inter-human relations based mostly on individualism and rivality. The results are individuals advancement, however, not team development. At the same time it is created big space for nonacceptance of the importance of responsible living.

Even though the nature of a great part of those attitudes is inborn, there is still a wide gap that must be bridge over by education.

The required education and preparation at this level is predominantly of psychological character and is focused on transforming an individual into a personality. The outcome of education is not very visible and that is why it is ignored to a considerable extent and thus not appreciated.

\section{2 Conditions for education for responsibly living}

As a individual anticipates a necessity of being prepared to take responsibility to the future building and can be ranked among persons of "R" group, then conditions for his education must be created. The crucial prerequisite is a standpoint of the top. It means government officials must not boycott, ignore or patiently tolerate the responsible behavior of people. It is them who should accept the the importance role of responsibility and subsequently the necessity of being ready to cope with them. A great emphasis must be laid on the role of the top (government officials) as it is just them who are finally responsible.

\section{3 Subsystems of education and training}

Well, which areas should the education of individuals for responsible behavior include?

The first area is the ability to perceive, observe and structure the surrounding events. An individual should use his imagination and ability to imbue others to follow his activity. Performance efficiency of an individual depends on his ability to tackle the problems. The second one includes the ability of communication. Targeted communication means a great support for the solution of even unexpected situations. The third one rests in trust. People respect an individual who they can rely on. Truthfulness, opinion steadiness and credibility are important values which the individual is expected to possess. The fourth one is own professional knowledge. These areas for the training of responsible behavior to the future should be caught at an early age of an individual.

\section{Can be business responsible to the future?}

Sustainability practitioners are familiar with the Triple Bottom Line (TBL) - people, planet and profit. The majority of people would agree that TBL tenants are the most important factors in shaping the sustainability of the business. 
All of that said, and despite its virtues, pursuit of the TBL alone cannot ensure achievement of the most important goal of a commercial entity; namely, its sustainability or continued survival for which, sustained financial growth is the single most important pre-requisite and judgment criterion.

Sustainability practitioners, while focusing on TBL, often fail to acknowledge the absolute importance of financial growth to the entity's continual well-being, in the absence of which, inflation alone will ensure the entity's demise to say nothing about existential challenges arising from continually increasing competition, changing market economic conditions. Finally, and most importantly, there is no a greater enemy of the sustainability movement than a failure (Savitz, Weber, 2006).

Yunus, the practical visionary who pioneered microcredit and, with his Grameen Bank, won the 2006 Nobel Peace Prize, has developed a visionary new dimension for capitalism which he calls "social business." By harnessing the energy of profit-making to the objective of fulfilling human needs, social business creates self-supporting, viable commercial enterprises that generate economic growth even as they produce goods and services that make the world a better place (Yunus, 2010). According to Scofield (2011) becoming a social entrepreneur is among the biggest decisions anyone can make and one of the most rewarding. When an individual puts his/her talent and hard work into amassing not capital but social capital, he/she'll finally see those changes he/she has been thinking, dreaming, and talking about take shape. Social entrepreneurs face challenges of hard commerce, fill special organizations function. Unlike the typical top-down, model-based approach to solving problems, social entrepreneurs work through a process of iterative learning, learning by doing, working with communities to find unique, local solutions to unique, local problems (Adámek, 2009). Elkington and Hartigan (2008) identify social entrepreneurs like the highly unconventional entrepreneurs who solve some of the world's most pressing economic, social, and environmental problems. They also show how these pioneers disrupt existing industries, value chains, and business models in the process creating fast-growing markets around the world.

\section{1 Triple Bottom Line}

The triple bottom line (or "TBL", "3BL", or "People, Planet, Profit") became the dominant approach for measuring organizational (and societal) success; economic, environmental and social. Similar UN standards apply to natural capital and human capital measurement to assist in measurements required by TBL, e.g. the ecoBudget standard for reporting ecological footprint.

In the private sector, a commitment to corporate social responsibility implies a commitment to some form of TBL reporting. This is distinct from the more limited changes required to deal only with ecological issues. The concept of TBL demands that a company's responsibility be to 'stakeholders' rather than shareholders. In this case, 'stakeholders' refers to anyone who is influenced, either directly or indirectly, by the actions of the business. According to the stakeholder theory, the business entity should be used as a vehicle for coordinating stakeholder interests, instead of maximising shareholder (owner) profit ${ }^{1}$.

\footnotetext{
${ }^{1}$ http://shivsthirdeye.blogspot.com/2011/01/bringing-about-enterprise.html [cit. 05. 02. 2011]
} 


\section{2 The Bottom Lines}

"People, Planet and Profit" are used to describe the triple bottom lines and the goal of sustainability.

"People" (Human Capital) pertains to fair and beneficial business practices toward labor and the community and region in which a corporation conducts its business. A TBL company conceives a reciprocal social structure in which the well being of corporate, labor and other stakeholder interests are interdependent.

A triple bottom line enterprise seeks to benefit many constituencies, not exploit or endanger any group of them. In concrete terms, a TBL business would not use child labor, would pay fair salaries, would maintain a safe work environment and tolerable working hours, and would not otherwise exploit a community or its labor force. Quantifying this bottom line is new, problematic and subjective. The Global Reporting Iniciative (GRI) has developed guidelines to enable corporations alike to comparably report on the social impact of a business.

"Planet" (Natural Capital) refers to sustainable environmental practices. A TBL company endeavors to benefit the natural order as much as possible or at the least do no harm and curtail environmental impact. A TBL endeavor reduces its ecological footpring by, among other things, carefully managing its consumption of energy and non-renewables and reducing manufacturing waste as well as rendering waste less toxic before disposing of it in a safe and legal manner. A triple bottom line company does not produce harmful or destructive products such as weapons, toxic chemicals or batteries containing dangerous heavy metals for example. In TBL thinking, an enterprise which produces and markets a product which will create a waste problem should not be given a free ride by society. It would be more equitable for the business which manufactures and sells a problematic product to bear part of the cost of its ultimate disposal. Ecologically destructive practices, such as overfishing or other endangering depletions of resources are avoided by TBL companies. Often environmental sustainablity is the more profitable course for a business in the long run. Arguments that it costs more to be environmentally sound are often specious when the course of the business is analyzed over a period of time. Generally, sustainability reporting metrics are better quantified and standardized for environmental issues than for social ones ${ }^{2}$.

"Profit" is the bottom line shared by all commerce. In the original concept, within a sustainability framework, the "profit" aspect needs to be seen as the economic benefit enjoyed by the host society. It is the lasting economic impact the organisation has on its economic environment.

\section{3 Arguments in favor of the concept TBL}

The following business-based arguments support the concept of TBL companies:

Reaching untapped market potential: TBL companies can find financially profitable niches which were missed when money alone was the driving factor. Examples include: ecotourism or geotourism in poor regions, creating Fair Trade jobs, fundraising or creating networking opportunities.

Adapting to new business sectors: Since many business opportunities are developing in the realm of social entrepreneurialism, businesses hoping to reach this expanding market, must design themselves to be financially profitable, socially beneficial and ecologically sustainable.

\footnotetext{
${ }^{2}$ http://www.entrepreneur.com/tradejournals/article/162103154.html [cit. 05. 02. 2011]
} 
For example, Fair Trade and Ethical Trade companies require ethical and sustainable practices from all of their suppliers and service providers. A business which is planning to work with Fair Trade or Ethical Trade companies, must design their business model to be TBL (Savitz, Weber, 2006).

Studies of nature's service and assessments of the value of Earth have tried to determine what might constitute an ecological or natural life deficit. The Kyoto Protocol relies on some measures of this sort, and actually relies on some value of life calculations that, among other things, are explicit about the ratio of the price of a human life between developed and developing nations (about 15 to 1). The motive of this number was to simply assign responsibility for a cleanup. As it is, people in developed nations can be said to benefit 15 times more from ecological devastation than in developing nations, in pure financial terms. They are thus obliged to pay 15 times more per life to avoid a loss of each such life to climate change-Kyoto seeks to implement exactly this formula, and is therefore sometimes cited as a first step towards getting nations to accept formal liability for damage inflicted on ecosystems shared globally ${ }^{3}$.

\section{4 Arguments against the concept}

While many people agree with the importance of good social conditions and preservation of the environment, there are also many who disagree with the 'Triple Bottom Line' as the way to enhance these conditions. Savitz and Weber (2006) also note the arguments against the concept of TBL. The main arguments against it may be summarised as:

Effectiveness: It is observed that concern for social and environmental matters is rare in poor societies (a hungry person would rather eat the whale than photograph it). As a society becomes richer its citizens develop an increasing desire for a clean environment and protected wildlife, and both the willingness and financial ability to contribute to this and to a compassionate society. Indeed support for the concept of the 'Triple Bottom Line' itself is said to be an example of the choices available to the citizens of a society made wealthy by businesses attending to business.

Business contributes most effectively to the improvement of all areas of society, social and environmental as well as economic.

Nationalism: Some countries adopt a nationalistic approach with the view that they must look after their own citizens first. This view is not confined to one sector of society, having support from elements of business, labor unions, and politicians.

Libertarian: As it is possible for a socially responsible person to sincerely believe that the 'Triple Bottom Line' is harmful to society, the libertarian view is that it would be arrogant to force them to support a mechanism for the improvement of society that may, or may not, be the best available. That is, those who would not force Greenpeace and the Salvation Army to generate a profit should not force businesses to take responsibilities outside their area of expertise.

Inertia: The difficulty of achieving global agreement on simulatenous policy may render such measures at best advisory - and thus not enforceable. For example, people may be unwilling to undergo a depression to replenish lost ecosystems.

\footnotetext{
${ }^{3}$ http://www.iisd.org/business/tools/principles_goodcorp.aspx [cit. 11. 02. 2011]
} 
Application: Because there is no single way to monetarially measure the benefits on the society and environment as there is with profit, it does not allow for businesses to sum across all three bottom lines. In this regard, it makes it difficult for businesses to recognize the benefits of using TBL for the company, itself.

\section{5 Implementing Triple Bottom Line Reporting}

Sustainability outcomes can be disclosed in a triple bottom line report, which provides information on societal and environmental outcomes as well as financial results. Due to its existential significance, contribution to growth is the ultimate judgment criterion used by businesses to evaluate every activity. This is relevant to sustainability in two ways. First, with any business that allocates more resources to sustainability, it is likely that this business perceives a closer relationship between sustainability and growth ${ }^{4}$. Second, when sustainability activities are not closely related to growth, they will most likely be the first to get cut, especially if the entity struggles to survive ${ }^{5}$.

Epstein provides an extraordinarily complete model for implementing sustainability initiatives. He covers the role of senior managers and corporate boards in leading and governing sustainability activities; organizational design issues that can improve sustainability; integration of social risk factors into capital investment, costing, and risk management systems; incentives and rewards to improve sustainability performance; identification and measurement corporate social, environmental, and economic impacts; and much more (Epstein 2008).

\section{Conclusion}

The basic output of this article is the highligting of importance of responsible approach to the future. This approach is required both from individuals and organizations. Mutual interlinkage of particular phenomena forces organisations, business and individuals to carefully economize their activities and to re-evaluate their responsible (or non responsible) behavior. Such tendency is inevitable if we are to face growing complexity of problems. The needs of new skills are arising. In concurrence thereon the importance of school education in the field of social responsibility namely on lowest levels is grown.

In presentment paper the author tried to point out some fields of the responsible citizen education and training. The author does not assert, that their specification is total or final. However she hope, that it can be the inspiration for the way of further education in this field. The approach to responsible living were applied at an individual. This fact is not at all determinated for the application of identical approach to any individual, at whose the author wants to investigate the level of its social responsible behavior.

For businesses, sustainability is a powerful and defining idea: a sustainable corporation is one that creates profit for its shareholders while protecting the environment and improving the lives of those with whom it interacts. It operates so that its business interests and the interests of the environment and society intersect. A sustainable business stands an excellent chance of being more successful tomorrow than it is today. Increasingly, businesses are expected to find ways to be part of the solution to the world's environmental and social problems. The best companies are finding ways to turn this responsibility into opportunity.

\footnotetext{
${ }^{4}$ http://english.turkcebilgi.com/Triple+Bottom+Line [cit. 05. 02. 2011]

${ }^{5}$ YEZERSKY, G., HALL, J. Why Pursuing the Triple Bottom Line is Not Enough. http://www.greenbiz.com/blog/2011/02/08/why-pursuing-triple-bottom-line-not-enough?page=0,0 [cit. 08.02. 2011]
} 
This statement may be confirmed by the existence of the system "Standard Responsible Company" which is a comprehensived and standardized system for measuring and benchmarking of Corporate Philanthropy and Corporate Community Investment. The holders of this award in the Czech Republic are for example GlaxoSmithKline (pharmacy), Metrostav (building), OKD, Advanced World Transport (logistics), E.ON (energy), Pivovary Staropramen, Tchibo Praha, Vodafone Czech Republic and others.

\section{Acknowledgement}

This article was created with the support from the student grant competition EkF Technical University of Ostrava, project no. SP 2011/51.

\section{References}

[1] ADÁMEK, P., 2009. Corporate social responsibility in European SMEs - myth or reality? Acta academica karviniensia. Karviná: OPF SLU, r. 2, s. 7 - 18. ISSN 1212-415X.

[2] BORNSTEIN, D. and S. DAVIS, 2010. Social Entrepreneurship: What Everyone Needs to Know. Oxford University, 176 s. ISBN 978-0-1953-9633-1.

[3] ELKINGTON, J., 1999. Cannibals With Forks. Wiley, 424 s. ISBN 978-1-8411-2084-3.

[4] ELKINGTON, J. and P. HARTIGAN, 2008. The Power of Unreasonable People: How Social Entrepreneurs Create Markets That Change the World. Harvard Business Review, 272 s. ISBN 978-1-4221-0406-4.

[5] EPSTEIN, M. J., 2008. Making Sustainability Work: Best Practices in Managing and Measuring Corporate Social, Environmental and Economic Impacts (Business). BerrettKoehler, 288 s. ISBN 978-1-5767-5486-3.

[6] KETS DE VRIES, M. and R. D. MILLER, 1984. The neurotic organization. San Francisco: Jossey-Bass, 211 s. ISBN 0-87589-606-5.

[7] MEADOWS, D. H., 2008. Thinking in Systems: A Primer. Chelsea Green, 240 s. ISBN 978-1-6035-8055-7.

[8] PAUCHANT, T. and I. MITROFF, 1988. I. Crisis Prone Versus Crisis Avoiding Organizations. Organization\&Environment. SAGE on-line publications, vol. 2 no. 1, s. 53-63.

[9] SAVITZ, A. W. and K. WEBER, 2006. The Triple Bottom Line: How Today's Best-Run Companies Are Achieving Economic, Social and Environmental Success - and How You Can Too. 3rd ed. San Francisco: Jossey-Bass, 291 s. ISBN 978-0-7879-7907-2.

[10]SCOFIELD, R., 2011. The Social Entrepreneur's Handbook: How to Start, Build, and Run a Business That Improves the World. McGraw-Hill, 272 s. ISBN 978-0-0717-5029-5.

[11]SCHEIN, E. H., 2010. Organizational culture and leadership. 4th ed. San Francisco: Jossey-Bass, 415 s. ISBN 978-0-470-19060-9.

[12]YEZERSKY, G. and J. HALL. Why Pursuing the Triple Bottom Line is Not Enough. http://www.greenbiz.com/blog/2011/02/08/why-pursuing-triple-bottom-line-notenough?page $=0,0$ [cit. 08.02.2011]

[13]YUNUS M., 2010. Building Social Business: The New Kind of Capitalism That Serves Humanity's Most Pressing Needs. PublicAffairs, 256 s. ISBN 1586488244.

[14]http://shivsthirdeye.blogspot.com/2011/01/bringing-about-enterprise.html [cit.05.02.2011] 
[15]http://www.entrepreneur.com/tradejournals/article/162103154.html [cit. 05.02.2011] [16]http://english.turkcebilgi.com/Triple+Bottom+Line [cit. 05.02.2011]

[17]http://www.iisd.org/business/tools/principles_goodcorp.aspx [cit. 11.02.2011] 